Pegem Journal of Education \& Instruction, 4(2), 2014, 75-90

Pegem Eğitim ve Öğretim Dergisi, 4(2), 2014, 75-90

www.pegegog.net

\title{
Opinions of Science Teachers about the Usage of Visual Media during Science and Technology Course*
}

\author{
Munise SEÇKIN KAPUCU ${ }^{\text {ta }}$ \\ ${ }^{a}$ Eskişehir Osmangazi University, Faculty of Education, Eskişehir/Turkey
}

\section{Article Info}

DOI: $10.14527 /$ pegegog.2014.010

Article history:

Received 19 November 2013

Revised 03 March 2014

Accepted 23 March 2014

Keywords:

Visual media,

Science teachers,

Phenomenology.

\begin{abstract}
This study aimed to find out the opinions of science teachers about the usage of visua media during science and technology course. Sample of the study consists of 15 science teachers who were working in Eskisehir, during 2012-2013 academic years. This research is designed using phenomenology approach, which is one of the qualitative research methods. Sample of the study was selected using purposive and easily accessible sampling; then criteria sampling was used to select teachers from the easily accessible sample. A semi-structured questionnaire, which has been developed by the researcher, was used for data collection. The interview form consists of two parts: First part includes questions about demographic characteristics whereas second part contains questions related with the sub-dimensions of the research. Content analysis was used on the data analysis. Based on the research findings, teachers stated that visual media enhances permanent learning, facilitates understanding, increases interest and curiosity and saves time. On the other hand, teachers may encounter several problems while using visual media, such as insufficiency of technological hardware, lack of subject-based images, existing visuals not being economical. According to the results of research, some recommendations have been made, which were supposed to contribute to increase the use of visual media while teaching topics, concepts and achievements in the science and technology course. In addition various suggestions have been developed for teachers, researchers, and educational policy makers, media organizations.
\end{abstract}

\section{Introduction}

Considering the dramatic change occurred in our lifestyle due to the rapid scientific and technological developments, the necessity of raising all individuals as science and technology literate is growing. In the vision of science and technology curriculum, it has been emphasized that all students should be trained as science and technology literate (MEB, 2006). This program aimed to train individuals in a way that they can understand texts, films and discussions that appear in written and visual popular media (Sürmeli, 2013). Visual media is effective in science training. Previous researches showed that science education can be learned from formal sources; however teachers may increase learning quality of the students by planning their courses including informal resources, such as written and visual media, TV shows, and films (Shaw \& Dybdahl, 2000).

The role of visual materials in learning is; increasing motivation by drawing attention, allowing sentimental responses, embodying the concepts, simplifying the understanding of difficult concepts, providing the opportunity of making observations, ensuring consistent presentation of related content at different times and being used over and over again (Mayer \& Moreno, 1998; Sorenson \& Dieter, 2005). For this reason, schools must address to the perception ability of the students via visual tools. In

\footnotetext{
This study is a developed version of a presentation presented at 22. National Educational Sciences Congress which is held by Eşkisehir Osmangazi University on September 5-7, 2013.

† Corresponding author: muniseseckin@hotmail.com
} 
addition, while teaching is performed using visual aids, students are learning having fun. These materials have various advantages for students to focus on the topics and to establish contacts with "real-world" problems.

Recently, in order to use technology effectively in science education, the usage of tablet PCs has become widespread in primary schools (Hashemzadeh \& Wilson, 2007). In Turkey, a large number of tablet PCs have been distributed to the teachers and students in the context of Movement of Enhancing Opportunities and Improving Technology (FATIH) project. This allows the usage of all kinds of visual information elements, such as videos, photos, maps, sound recordings and films records, as educational materials. Students prefer creative and interesting learning methods; film is one of them (Weber \& Silk, 2007). Films can completely present abstract information in an integrated manner, covering all relevant elements or can convert them into real life (Birkok, 2008). Meanwhile the function of the film as a tool is increasing and expanding. Although the main purpose of the film is to have a good time, it can be used very effectively in education (Blasco, Moreto, Roncoletta, Levites \& Janaudis, 2006). Film is the audiovisual form of storytelling. One of the most important reasons of the films to be effective is the new generation being very familiar with visual media (Luis Alvarez, Miller, Levy, \& Svejenova, 2004). Kuzma (2001), in his paper, stated that current young generation spend most of their time in front of the television, computers, cinema halls; they prefer audio and video communication and expression to written material; thus considering this approach of the youngsters, the use the films in education by trainers becomes natural.

Finally, the application and performance of visual tools, which are used in all areas of education and training, became a necessity and standard in many disciplines (such as computer, vocational training, and science education) (Arıkan, 2009). Whether or not teachers teaches through printed materials, the use of communication tools is rapidly changing in almost every part of the world and this fact requires the usage of communication tools and visual materials in the classroom context (Hammerberg, 2001).

How much science teachers benefit from the visual media was wondered. Thus, this study aimed to determine the opinions of science teachers about the usage of visual media during their courses. This study is expected to contribute to the development of visual media awareness of teachers, area specialists and educational policy makers.

The main purpose of this study was to determine the opinions of science teachers about the usage of visual media during their courses. For this purpose, the following questions were addressed:

- What are the opinions of teachers about the contribution of visual media to science education?

- What are the opinions of science teachers about the positive and negative sides of using visual media in science courses?

- What do teachers think about the problems that may be encountered using visual media in science education?

- What are the teachers' suggestions about more effective usage of visual media in science courses?

\section{Method}

\section{Research Design}

This research was designed using phenomenology approach, which is one of the qualitative research methods. The phenomenon, which has been set as the focus of this research, was the use of visual media during courses. Phenomenology deals with how people perceive a phenomenon, how they remember it, how they evaluate it and how they communicate it with other persons (Patton, 2001). 


\section{Participants}

Study group consists of 15 science teachers who were working in Eskisehir, during 2012-2013 academic years. Participants were selected using purposive and easily accessible sampling; then criteria sampling was used to select teachers from the easily accessible sample. The main criterion for the selection of the teachers was set as teaching science and technology course. A total of 15 science and technology teachers, from five different schools have participated to the study, 8 of them were women (53.3\%) whereas 7 of them were men (46.6\%).

\section{Instrument}

In phenomenology researches, the main data collection tool is interviews (Yıldırım \& Şimşek, 2008). A semi-structured questionnaire, which has been developed by the researcher, was used for data collection.

\section{Data Analysis}

Content analysis was used for analyzing the data. Structural, descriptive, in vivo and process coding have been performed. The data gathered during the research was coded in the analysis phase and was classified under various themes. At the end of analysis phase, both researchers have examined the analysis, which they have conducted separately, and agreed on the codes and themes. Data was reported using direct connotation from teacher's opinions.

\section{Results}

According to the results of the research, science and technology teachers mostly stated that visual media enhances permanent learning and facilitates understanding. In addition, teachers also shared their opinions that visual media facilitates learning, facilitates teacher's lecture, makes lessons more amusing, increases curiosity and enhances permanent learning. On the other hand, teachers often believe that visual media causes distractions. Regarding the problems that may be encountered due to the usage of visual media in science education, teachers have mostly emphasized the insufficiency of technological equipment.

\section{Discussion, Conclusion \& Implementation}

Science and technology teachers mostly stated that visual media enhances permanent learning and facilitates understanding. In the study performed by Yalçın, Yiğit, Sülün, Bal, Başbuğ and Aktaş (2003), where the effect of visual materials on understanding "knowing the matter" topic has been investigated, it has been found that visual materials were effective on teaching the perceptible concepts such as wind, air, heat, electricity. In addition, teachers expressed their opinions that visual media was increasing interest and curiosity. In addition, saving time and reducing the workload of teachers were also underlined among the teachers' opinions about the contribution of visual media to science education. In a study conducted by Öztürk, Demir and Dökme (2011), it has been concluded that technological tools may be useful because they save time, draw attention, provide visuality and persistence in learning.

It has been seen that teachers expressed positive opinions, such as visual media facilitates learning, facilitates lecture of the teacher, makes the course more amusing, increases curiosity and enhances permanent learning. In a study conducted by Mandıracıoğlu, Hassoy and Karababa (2011) first class students evaluated positively the following features, regarding the usage of films; with a film, subjects get more permanent in mind, being visual, shows concrete examples from real life, allows reinforcement 
and understanding of theoretical courses, allows the participation of students, being interactive, experiences a fun and enjoyable learning, facilitates the understanding and learning of the subject.

Regarding the problems that may be encountered due to the usage of visual media in science education, teachers mostly emphasized the insufficiency of technological equipment. Teachers' suggestion about the effective usage of visual media in science courses were; getting in-job training and the visuals being provided by the Ministry of Education. In a qualitative study conducted by Ökten and Horzum (2011), teachers expressed that they were unable to acquire the required technological competence due to the rapid development of technology and ongoing changes; despite taking computer courses, they could only provide basic level of computer proficiency to their students. But current education programs and especially FATIH project expect teachers to use technology effectively in education. Teachers stated that they could not reach an adequate level of technology and computer usage knowledge/skill during the pre-service courses (Erdemir, Bakırcı \& Eyduran, 2009).

There are some suggestions developed according to the findings of the research. Teachers stated that visual media enhances permanent learning, facilitates understanding, increases interest and curiosity and saves time. Efforts should be made to enable the teachers to benefit from visual media during the courses. Teachers may encounter various problems while using visual media in their courses, such as insufficiency of technological hardware, lack of subject-based images, existing visuals not being economical. In order to solve these problems, comprehensive visuals should be prepared for each subject, the curriculum should include visual learning, and teachers should use visual learning methods, such as films, animations, documentaries, cartoons, in their courses. Teacher should be trained for the use of technological equipment. Visuals that can be associated with each unit, topic, or gain should be prepared and uploaded to a system, which can be accessed by the teachers, by the Ministry of Education. 
Pegem Journal of Education \& Instruction, 4(2), 2014, 75-90

Pegem Eğitim ve Öğretim Dergisi, 4(2), 2014, 75-90

www.pegegog.net

\section{Fen ve Teknoloji Dersinde Görsel Medya Kullanımına Yönelik Fen Bilgisi Öğretmenlerin Görüşleri*}

\section{Munise SEÇKIN KAPUCU ${ }^{\text {ta }}$}

${ }^{a}$ Eskişehir Osmangazi Üniversitesi, Eğitim Fakültesi, Eskişehir/Türkiye

\section{Makale Bilgisi}

DOI: $10.14527 /$ pegegog.2014.010

Makale geçmişi:

Geliş 19 Kasım 2013

Düzeltme $\quad 03$ Mart 2014

Kabul 23 Mart 2014

Anahtar kelimeler:

Görsel medya,

Fen bilgisi öğretmenleri,

Fenomenoloji.

\section{Öz}

Bu çalışmada fen ve teknoloji dersinde görsel medya kullanımına yönelik fen bilgisi öğretmenlerinin görüşlerinin belirlenmesi amaçlanmıştır. Çalışmaya 2012-2013 eğitim öğretim yılında Eskişehir'de görev yapan 15 fen bilgisi öğretmeni katılmıştır. Bu araştırma nitel araştırma yöntemlerinden biri olan olgubilim (fenomenoloji) yaklaşımı ile desenlenmiştir. Araştırmanın örneklem grubu seçilirken amaçı örneklem yöntemlerinden amaçlı ve kolay ulaşılabilir örnekleme kullanılmıştır. Kolay ulaşılabilir örnekleme içinden de öğretmenlerin belirlenmesi için ölçüt örneklem kullanıımıștır. Verilerin toplanmasında araştırmacı tarafından gelişstirilen yarı yapılandırılmış görüşme formu kullanılmıştır. Görüşme formu iki kısımdan oluşmaktadır. Illk kısımda demografik özelliklere ilişkin sorular ikinci kısımda ise araştırmanın alt problemleriyle ilgili sorular yer almıştır. Verilerin analizinde içerik analizi kullanıımıştır. Araştırma sonuçlarına göre öğretmenler görsel medyanın kalıcı öğrenmeye neden olduğunu, anlamayı kolaylaştırdığııı, ilgi ve merakı artırdığını ve zaman tasarrufu sağladığını vurgulamışlardır. Ayrıca öğretmenler derslerinde görsel medya kullanırken teknolojik donanım yetersizliği, konulara göre görsellerin olmaması, mevcut görsellerin ekonomik olmaması gibi sorunlarla karşıaşabilmektedir. Araş̧ırma sonuçları doğrultusunda fen ve teknoloji dersinde yer alan konuların, kavramların ve kazanımların öğretilmesinde görsel medya kullanımının artııımasına katkı sağlayacağı düşünülen önerilere yer verilmiştir. Ayrıca öğretmenlere, araştırmacılara ve eğitim politikalarını belirleyenlere, medya kuruluşlarına yönelik çeşitli öneriler geliştirilmiştir.

\section{Giriş}

Son yıllarda, sosyal medya bilgi ve iletişimizi etkileyecek şekilde yaşamımızda büyük yer edinmiştir. Modern sosyal yaşamda televizyon, sinema, video, bilgisayar ve resimli metinler gibi görsel unsurlar tarafından kuşatıımış durumdayız. Evde, işte, okulda ya da dışarıda birçok görsel uyarıcıyla karşılaşmaktayız. Bununla birlikte yeni nesil doğar doğmaz televizyon, bilgisayar, internet gibi görsel medya araçlarıyla tanışmakta ve bu araçlarla zaman geçirmek yeni neslin en büyük eğlencesi olmaktadır.

Son zamanlarda teknolojinin gelişmesiyle birlikte, her alanda olduğu gibi eğitim alanında da teknolojik gelişmelerin yansımalarını özellikle ilköğretim programlarında görmek mümkündür. Günümüzde yaşanan hızlı bilimsel ve teknolojik gelişmelerin yaşam şeklimizi önemli ölçüde değiştirdiği göz önünde bulundurulduğunda bütün bireylerin fen ve teknoloji okuryazarı olarak yetişmesinin gerekliliği ön plana çıkmaktadır. Fen ve teknoloji öğretim programının vizyonunda da bütün öğrencilerin fen ve teknoloji okuryazarı olarak yetişmesi vurgulanmıştır (MEB, 2006). Bu program çerçevesinde yazılı ve görsel popüler medyada yer alan yazıları, filmleri ve tartışmaları anlayabilen bireylerin yetişmesi hedeflenmiştir (Sürmeli, 2013). Fen eğitiminde görsel medya etkili olmaktadır. Araştırmalar da fen

\footnotetext{
* Bu çalışma 5-7 Eylül 2013 tarihleri arasında Eskişehir Osmangazi Üniversitesi’nin düzenlediği “22. Ulusal Eğitim Bilimleri Kongresi"nde sunulan sözlü bildirinin geliştirilmiş halidir.
}

'Yazar: muniseseckin@hotmail.com 
eğitiminin formal kaynaklardan öğrenilebildiği gibi yazılı, görsel medya, televizyon programları, filmler gibi informal kaynakları kullanarak derslerini planlayan öğretmenlerin, öğrencilerinin öğrenme kalitesini artırabileceklerini göstermiştir (Shaw ve Dybdahl, 2000).

Görsel medya, hangi farklı boyutlarda olursa olsun bireyi etkilemekte ve eğitim sistemlerinin de vazgeçilmez araçlarından biri durumuna gelmektedir. Görsel ve işitsel olarak öğrenmelere yardımcı olan televizyon ve sinema gibi etkili uyarıcı durumundaki bu araçlar, bilgi ve teknolojinin temeli olan fen alanlarında kullanılmasıyla kendi fonksiyonlarını gerçek anlamda yerine getirmiş olacaktır. Görsel materyallerin öğrenmedeki rolü; dikkati çekerek güdülenmeyi arttırması, duygusal tepkiler vermeyi sağlaması, kavramları somutlaştırması, anlaşıması zor kavramları basitleştirmesi, gözlem yapma olanağı sağlaması, farklı zamanlarda birbiri ile tutarlı içeriğin sunulmasını sağlaması, tekrar tekrar kullanılabilmesidir (Mayer ve Moreno, 1998; Sorenson ve Dieter, 2005). Bu sebeple de okullar, görsel araçlarla öğrencilerin algılama yeteneklerine cevap vermelidir. Ayrıca görsel materyaller kullanılarak yapılan öğretimde öğrenciler eğlenerek öğrenirler. Bu materyaller öğrencinin konuya odaklanmasında ve "gerçek-dünya" problemleriyle bağlantı kurmasında üstünlük sağlamaktadır.

Fen ve teknoloji dersinde öğrencilere programda yer alan kazanımları kazandırmak için çeşitli öğrenme kaynakları kullanılmaktadır. Fen eğitiminde daha fazla uyarıcıyla ders işlemenin öğrenmeyi daha etkili ve kalıı hale getireceğine inanılmaktadır. Soyut kavramların somutlaştııılmasında görselişitsel araçlar etkin rol oynamaktadır. Fen ve teknoloji programında daha çok görsel öğrenme-öğretme araçlarına vurgu yapılmıştır. Son zamanlarda etkili bir şekilde fen öğretiminde teknolojiden yararlanabilmek için tablet bilgisayarların kullanımı ilköğretim okullarında da yaygınlaşmaya başlamıştır. (Hashemzadeh ve Wilson, 2007). Türkiye'de Fırsatları Arttırma ve Teknolojiyi İileştirme Hareketi (FATiH) Projesi kapsamında öğretmen ve öğrencilere çok sayıda tablet bilgisayar dağıtılmıştır. Bununla birlikte videolar, resimler, haritalar, ses kayıtları, film kayıtları gibi her tür görsel bilgi unsuru bir eğitim malzemesi olarak kullanılabilmektedir. Öğrenciler yaratıcı, ilgilerini çeken öğrenme yöntemlerini daha çok tercih etmektedirler, film de bunlardan biridir (Weber ve Silk, 2007). Filmler, soyut bilgileri ilgili tüm unsurlarıyla bir bütünlük içinde eksiksiz olarak canlandırabilmekte veya gerçek bir hayata dönüştürebilmektedir (Birkok, 2008). Bu arada film aracı ve işlevi de giderek gelişmekte ve yaygınlaşmaktadır. Filmin birincil amacı güzel vakit geçirmek olsa da eğitimde çok etkin kullanılabilir (Blasco, Moreto, Roncoletta, Levites ve Janaudis, 2006). Film, hikâye anlatımının görsel-işitsel şeklidir. Derslerde filmlerin etkili olmasının en önemli sebeplerinden birisi, yeni nesillerin görsel medyaya çok aşina olmalarıdır (Luis Alvarez, Miller, Levy, ve Svejenova, 2004). Kuzma (2001) makalesinde, şimdiki genç neslin vaktinin çoğunu televizyon, bilgisayar, sinema salonlarında geçirmekte olduğunu, yazılı materyalden çok sesli ve görüntülü iletişim ve ifadeyi tercih ettiğini ve eğiticilerin de gençlerin bu yaklaşımını göz önüne alarak filmleri eğitimlerinde kullanmasının doğal olduğu yorumunu yapmaktadır.

Son olarak, eğitim ve öğretimin her alanında kullanılmakta olan görsel araçların etkin olarak çalışılması ve uygulanması artık bir zorunluluk ve hatta birçok alanda (bilgisayar, mesleki eğitim, fen bilgisi öğretimi gibi) alışılagelmiş bir olgu olmuştur (Arıkan, 2009). Öğretmenler basılı materyaller aracılığıyla ders versinler ya da vermesinler iletişim araçlarının kullanımı dünyanın hemen her yerinde hızla değişmekte ve bu gerçek de iletişim araçlarının ve görsel materyallerin sınıf içi ortamlarda kullanılmalarını zorunlu kılmaktadır (Hammerberg, 2001).

Fen bilgisi öğretmenlerinin görsel medyadan yaralanma durumları merak edilmektedir. Bu nedenle bu çalışmada fen öğretmenlerinin görsel medyayı derslerinde kullanımına yönelik görüşleri belirlenmeye çalışılmıştır. Bu çalışmanın öğretmenlerin, alan uzmanlarının ve eğitim politikalarını belirleyenlerin görsel medya ilgili farkındalıklarını geliştirmeye katkı sağlayacağı düşünülmektedir.

Bu araştırmanın temel amacı fen bilgisi öğretmenlerinin derslerinde görsel medya kullanımına ilişkin görüşlerini belirlemektir. Bu amaç doğrultusunda aşağıdaki sorulara yanıt aranmıştır:

- Görsel medyanın fen eğitimine katkıları konusunda öğretmenlerin görüşleri nelerdir?

- Fen derslerinde görsel medya kullanmanın olumlu ve olumsuz yanları hakkında fen bilgisi öğretmenlerinin görüşleri nelerdir? 
- Öğretmenler fen eğitiminde görsel medyadan yararlanmada karşılaşılabilecek sorunlara ilişkin olarak neler düşünmektedirler?

- Görsel medyanın fen derslerinde etkili bir biçimde kullanılabilmesi konusunda öğretmenlerin önerileri nelerdir?

\section{Yöntem}

\section{Araştırma Modeli}

$\mathrm{Bu}$ araştırma nitel araştırma yöntemlerinden biri olan olgubilim (fenomoloji) yaklaşımıyla desenlenmiştir. Bu araştırma sürecinde üzerine odaklanılan olgu derslerde görsel medya kullanımı olarak belirlenmiştir. Insanların bireysel veya birlikte yaşamış oldukları deneyimleri nasıl anlamlandırdıklarını, algıladıklarını ve zihinlerine nasıl transfer ettiklerini araştıran bilim dalına olgu bilim denmektedir. Olgu bilim insanların bir olguyu nasıl algıladığı, nasıl tarif ettiği, nasıl hatırladığı, nasıl değerlendirdiği ve diğer insanlara nasıl bir dil kullanarak aktardığı konularıyla ilgilenmektedir (Patton, 2001).

\section{Katılımcılar}

Çalışmaya 2012-2013 eğitim öğretim yılında Eskişehir'de görev yapan 15 fen bilgisi öğretmeni katılmıştır. Araştırmanın örneklem grubu seçilirken amaçlı örneklem yöntemlerinden amaçı ve kolay ulaşılabilir örnekleme kullanılmıştır. Kolay ulaşılabilir örnekleme içinden de öğretmenlerin belirlenmesi için ölçüt örneklem kullanılmıştır. Araştırmaya katılan öğretmenlerin seçiminde fen ve teknoloji dersine girmeleri temel ölçüt olarak belirlenmiştir. Çalışmaya 8'i (\%53.3) kadın, 7'si (\%46.6) erkek olmak üzere beş farklı okuldan toplam 15 fen ve teknoloji öğretmeni katılmışır.

\section{Veri Toplama Aracı}

Olgubilim araştırmalarında başıca veri toplama aracı görüşmedir (Yıldırım ve Şimşek, 2008). Bu nedenle bu çalışmada verilerin toplanması amacıyla araştırmacı tarafından geliştirilen yarı yapılandıııımış görüşme formu kullanılmıştır. Görüşme formu iki kısımdan oluşmaktadır. Illk kısımda demografik özelliklere (derse girdiği sınıf düzeyine, cinsiyete, okula) ilişkin sorular ikinci kısımda ise araştırmanın alt problemleriyle ilgili sorular yer almıştır. Yarı yapılandırılmış görüşme formlarının oluşturulmasında ilgili alanyazın taranmıştır. Araştırmacı tarafından hazırlanan beş açık uçlu soru ile ilgili konu uzmanlarının görüşü alınmıştır. Uzmanların görüşleri doğrultusunda görüşme formu yeniden düzenlenmiştir.

\section{Verilerin Toplanması}

Veri toplama sürecinde çalışma grubunu oluşturan öğretmenlerle yüz yüze görüşülmüştür. Öğretmenlerle yapılan görüşmeler ortalama 20 dakika sürmüştür. Görüşmeler katılımcıların bilgisi dâhilinde ses kayıt cihazı ile kayıt altına alınmıştır. Görüşme sırasında öğretmenleri yönlendirici olmaktan ve araştırmanın veri toplama sürecini olumsuz etkileyebilecek durumlardan kaçınılmıştır. Katılımcıların kimliklerinin gizli kalması amacıyla kodlamalardan yararlanılmıştır.

\section{Verilerin Analizi}

Verilerin analizinde içerik analiz kullanılmıştır. Olgubilim araştırmalarında veri analizi, yaşantıları ve anlamları ortaya çıkarmaya yöneliktir (Yıldırım ve Şimşek, 2008). Birinci ve ikinci düzey kodlamalardan yararlanılmışır. Yapısal, betimsel, invivo ve süreç kodlamalar kullanılmışır. Kodlamalar yapılırken Nvivo bilgisayar yazıımı kullanılmıştır. Araştırmada elde edilen veriler analiz sürecinde kodlanmış ve amaçlara dayalı olarak temalar altında toplanmıştır. Yoğun bir veri seti içinde araştırmacıların seçici olması ve 
araştırma amaçları çerçevesinde kodlama yapabilmesi araştırmanın geçerliliğini de olumlu yönde etkilemektedir (Yıldırım ve Şimşek, 2008, s.223). Veriler görüşlerden doğrudan alıntılara yer verilerek raporlaştırımıştır. Araştırmada her bir öğretmen adayına bir kod ad verilmiş, raporlaştırmada görüşlerden doğrudan alıntılar yapılırken bunlar kullanılarak katılımcılar gizli tutulmuştur. Analiz süreci sonunda iki araştırmacı ayrı ayrı yapmış oldukları analizleri inceleyerek kod ve temalar üzerinde uyum sağlamışlardır. Katılımcıların verdikleri yanıtların sıklığına göre, başlıklar altında bir sınıflama ve bu sınıflamaya bağlı olarak frekans sıklığı analiz edilmiştir.

\section{Bulgular}

Bu bölümde araştırmanın amacı doğrultusunda elde edilen bulgular öğretmen görüşlerinden oluşan doğrudan alıntılarla desteklenerek verilmektedir.

\section{Öğretmenlerin Görsel Medyanın Fen Eğitimine Katkıları}

Fen ve teknoloji öğretmenlerine göre görsel medyanın fen eğitimine katkıları bilişsel, duyuşsal ve ekonomik olma temaları altında ele alınmıştır (Tablo 1). Bilişsel tema altında öğretmenler çoğunlukla görsel medyanın kalıcı öğrenmelere neden olduğu ile ilgili görüş belirtmişlerdir. Bir katılımcı (K-11) "Görsel medyadan alınan bilgiler, kalıcı olması yönünde faydalanılır" şeklinde görsel medyanın faydasını vurgularken, bir başka katılımcı (K-9) "Özellikle animasyonlar öğrencinin olayı anlamasını kolaylaştırıp bilgiyi ve olayı öğrenci zihninde daha kalıcı hale getirebilmekte" şeklinde düşüncesini ifade etmiştir. Diğer bir katılımcı (K-3) ise "Olumlu yönleri her şeyden önce beş duyu organına hitap ettiği için yararlıdır. Unutulmaz tıpkı hiç unutamadığımız filmler, olaylar gibi..." şeklinde görüşünü dile getirmiştir. Bilişsel tema altında çoğunlukla tekrarlanan diğer bir görüş ise görsel medyanın anlamayı kolaylaştırdığı yönündedir. Bir katılımcı (K-7) "Konuların kavranmasında daha etkileyici rol oynuyor" şeklinde görüş bildirirken diğer bir katılımcı (K-4) "Fen ve teknoloji dersinde işlenen konular hakkında hazırlanmış olan power-pointler, flash sunumlar en azından konu ile ilgili resimler öğrencinin konuları daha iyi anlamasına katkısı çok fazla" şeklinde görüş bildirmiştir. Başka bir katılımcı (K-1) ise "Dersin işlenişi sırasında konu ile ilgili öğrencinin seviyesine uygun medya araçlarının kullanılması öğrenmeyi kolaylaştırabileceği gibi öğrencinin genel kültürüne de katkı sağlayabilir" şeklinde görüşünü bildirirken öğrenci seviyesine uygunluğa vurgu yapmıştır. Bilişsel tema altında en az vurgulanan alt temalar ise hatırlanma ve farklı düşünmedir. Hatırlanma alt teması için bir katılımcı (K-11) görsel medyanın "Geçmiş konuların hatırlanmasını kolaylaştırdığı" şeklinde görüşünü ifade ederken başka bir katılımcı (K-12) "Mevcut eğitim programlarında medya okuryazarlığının gereksinimlerinden söz edilmekte fakat bu alanda etkili bir çalışma yapıldığını düşünmüyorum. ilgi alanı içerisindeki görsel medya kaynaklarına ulaşabilen öğrencilerin farklı düşünmeye yönlendirme gibi katma değeri vardır" şeklinde görüşünü belirtirken farklı düşünmeye vurgu yapmıştır.

Tablo 1.

Görsel Medyanın Fen Eğitimine Katkıları.

\begin{tabular}{lll}
\hline Tema & Alt tema & $\mathbf{f}$ \\
\hline Bilişsel & Kalıcı & 8 \\
& Anlamayı kolaylaştırma & 7 \\
& Hatırlanma & 2 \\
& Farklı düşünme & 2 \\
\hline Duyuşsal & İgi ve merakı artırma & 7 \\
& Dikkat çekici olma & 1 \\
\hline Ekonomik olma & Zaman tasarrufu & 4 \\
& Öğretmenin yükünü azaltma & 1 \\
\hline
\end{tabular}


Duyuşsal tema altında en çok tekrarlanan görüş görsel medyanın ilgi ve merakı artırdığı yönündedir. Bu alt tema için bir katıımcı (K-5) "Bilime ilgisi olan öğrencilerin merakını artıııyor. Özel TV kanallarındaki belgeseller, deneyler konusu geldikçe derslerde çok anlatılıyor. Bunun için fen dersi konularını içeren kısa filmler hazırlanıp, derslerde gösterilebilir" şeklinde görüşünü belirtirken diğer bir katılımcı (K-11) "Fen derslerinde öğrenciler görsel medyaya daha ilgili oluyor ve merak uyandırır" şeklinde görüşünü belirtmiştir. Öğretmenler görsel medyanın öğrencilerin ilgisini çektiğini dile getirmişlerdir. Duyuşsal tema altında en az tekrarlanan görüş ise dikkat çekici olmadır. Bu konu ile ilgili bir öğretmenin (K-10) görüşü "Dikkati daha kolay çekebilir" yönündedir.

Ekonomik olma alt teması altında ifade edilen öğretmen görüşleri arasında görsel medyanın zaman tasarrufu sağlama ve öğretmenin yükünü azaltma vurgulanmıştır. Zaman tasarrufu alt teması ile ilgili bir öğretmenin (K-2) görüşü "Zamandan kazanç sağlamasını sağlar" şeklindeyken diğer bir öğretmenin (K10) görüşü "Ön hazırlık iyi yapıldığından zaman tasarrufu sağlayabilir" şeklinde olmuştur. Öğretmenlerin görsel medyanın öğretimde zamanın etkili kullanılmasına vurgu yaptıkları görülmektedir. Görsel medyanın fen eğitimine katkıları konusunda görüş bildiren bir öğretmenin (K-13) görüşü ise şu şekildedir: "Öğretmenin yerini doldurmaz sadece gücünü artırır, yükünü azaltır".

\section{Fen Derslerinde Görsel Medya Kullanmanın Olumlu ve Olumsuz Yanları}

Fen derslerinde görsel medya kullanmanın olumlu ve olumsuz yanları ile ilgili görüşler Tablo 2'de görülmektedir. Görsel medya ile ilgili olarak öğretmenler çoğunlukla öğrenmeyi kolaylaştırma, öğretmenin anlatımını kolaylaştırma, dersi zevkli hale getirme, merakı artırma ve kalıı öğrenmeyi sağlama şeklinde olumlu görüş bildirmişlerdir. Öğrenmeyi kolaylaşıırma alt temasıyla ilgili bir öğretmenin (K-4) görüşü "Fen ve teknoloji dersinde konu ile ilgili hazırlanmış olan görsellerin olumlu katkısı çok fazla öğrenmeyi kolaylaştııı" şeklindeyken bu görüşü paylaşan diğer bir öğretmenin (K-10) görüşünde ise "Hem görsel hem işitsel olması öğrenmenin daha kolay olmasını sağlaması" görsel medyanın görsel ve işitsel olmasına vurgu yapılmaktadır. Öğretmenin anlatımını kolaylaştırmayla ilgili bir öğretmenin (K-9) görüşü "Slaytta anlatımlarda konuyla ilgili özet bilgi ve maddelerin yansıtılması öğretmenin anlatımını kolaylaştırmakta" şeklindeyken diğer bir öğretmenin (K-10) görüşü ise "Ders anlatımını öğretmen açısından kolaylaştırdığı" şeklindedir. Dersi zevkli hale getirme ile ilgili bir öğretmenin (K-11) görüşü ise "Öğretmenin yapması gereken dersine özel etkinliklerin yanında (deneygözlem), görsel medyadan da yararlanması, dersin işlenişinde ilgiyi artırmakta ve zevkli hale getirmektedir" şeklindeyken bu görüşü paylaşan diğer bir görüş (K-13) ise "Öğrenci için dersi monotonluktan kurtarıp eğlenceli hale getirir bu da derse olan ilgiyi ve başarıyı artııı" şeklindedir. Öğretmenler merakı artırma ve kalıcı öğrenme ile ilgili de öğretmenler görüş bildirmişlerdir. Merakı artırma ile ilgili bir öğretmenin (K-14) görüşü şu şekildedir: "Görsel medya fen derslerinde öğrencileri meraka ve araştırmaya yönlendirebilir". Kalııı öğrenme ile ilgili de başka bir öğretmen (K-12) görsel medyanın "etkileyici ve kalıcı öğrenme" sağladığına vurgu yapmışır. Görsel medyanın olumlu yanları ile ilgili olarak en az tekrarlanan görüşler ise özet bilgi sunma, öğretimde düzenliliği sağlama, öğretimin verimliliğini arttırma, genel kültürü artırma, motivasyonu artırma, dikkat çekme ile ilgi ve başarıyı artırma yönünde olmuştur.

Öğretmenler çoğunlukla görsel medyanın dikkat toplamada, öğrenci seviyesine uygun olmada ve zaman ayarlamada sorun yaratacağıyla ilgili olumsuz görüş belirtmişlerdir. Öğretmen görüşleri çoğunlukla görsel medyanın dikkat toplamada sıkıntı olacağı yönündedir. Dikkat toplama ile ilgili görüş belirten bir öğretmen (K-5) görüşünü "Ancak zaman geçirmek isteyen öğrenciler uyumak için firsat olarak değerlendiriyorlar. Bu nedenle konuların uzman kişiler tarafından hazırlanıp çok ilginç örneklerle donatılıp ilgisiz ögrencileri de konulara çekmek gerekiyor" şeklinde ifade ederken diğer bir öğretmen (K6) ise "Bazı öğrenciler dikkatlerini toplayıp, izlemiyor" şeklinde görüş bildirmiştir. Başka bir öğretmen (K10) de "Sık uygulandığında dikkatin azalması" na neden olduğunu ifade etmiştir. Bir öğretmen (K-11) ise görsel medyanın dikkat dağıtmanın yanında ilgi dağıttığına da şu sözlerle vurgu yapmıştır: "Sırf diğer etkinliklerin dışında sırf belgesel ve projeksiyonla ders anlatmak uzun süreli ilgiyi kaybetmek, dikkati 
dağıtmaktadır". Öğrenci seviyesine uygun olmama alt temasıyla ilgili bir öğretmenin (K-1) görüşü "Medya araçlarının öğrenci seviyesinin üzerinde olması" şeklindeyken bu görüşü paylaşan diğer bir öğretmenin görüşü (K-4) "İzletilen görsellerin seviye üzerinde olması öğrenci de olumsuzluk yaratabilir" şeklinde olmuştur. Bu görüşleri destekleyen diğer bir öğretmenin (K-14) görüşü ise "Öğrencilerin fen dersine ilgilerini artırabileceği gibi hangi bilgiyi hangi yaşta alacağını bilemeyecekleri için bazı sorunlar ortaya çıkabilir. Mesele biz okulda yaş seviyesine göre konuları vermeye çalışırken 6. sınıftaki bir çocuk televizyonda klonlama ile ilgili bir yenilik duyduğunda bunu anlamaz ve fene ilgisi azalabilir. Kişi bilmediğine düşmandır çocuk da anlayamayacağı bir yayınla karşılaştığında yanında onu yönlendirecek bilinçli bir kişi de yoksa anlayamadığını ya dinlemeyecektir ya da sinirlenecektir. Bunun için öğretmenlerin kontrollü bir şekilde bilimsel haberleri paylaşmaları bu konudaki rehberlikleri çok önemlidir. Bu düzgün olursa görsel meyde fen derslerinde öğrencileri meraka ve araştırmaya yönlendirebilir" şeklindedir. Görsel medyayla ilgili öğretmenlerin olumsuz görüşleri arasında çoğunlukla belirtilen diğer bir alt tema ise görsel medyanın zamanı ayarlamada sorun yarattı̆̆ı yönündedir. Bu konu ile ilgili bir katılımcı (K-10) "Zaman ayarlanmasının iyi yapılmaması durumunda konuların yetiştirilememesi" ne vurgu yaparken bu görüşü destekleyen diğer bir görüş (K-13) ise "Öğretmen derste çok fazla görsel medya kullandığı takdirde zaman sıkıntısı yaşayarak müfredatı yetiştiremeyebilir" şeklinde olmuştur. Görsel medyayla ilgili öğretmenlerin olumsuz görüşleri arasında en az tekrarlanan görüşler ise görsel medyanın konu ile ilişkilendirilememesi, görsel medya ile not tutturulamaması, güncel materyal bulunamaması, görsel medyanın anlam karmaşasına yol açması, görsel medyanın sıkılmaya neden olması, bir süre sonra diğer metotların sıkıcı ve sıradan gelmesi ile görsel medyanın başarının düşmesine neden olmasıyla ilgili olmuştur.

Tablo 2.

Fen Derslerinde Görsel Medya Kullanmanın Olumlu ve Olumsuz Yanları.

\begin{tabular}{lll}
\hline Tema & Alt tema & $\mathbf{f}$ \\
\hline Olumlu & Öğrenmeyi kolaylaştırma & 3 \\
& Öğretmenin anlatımını kolaylaştırma & 2 \\
Dersi zevkli hale getirme & 2 \\
Merakı artırma & 2 \\
Kalıcı öğrenme & 2 \\
Özet bilgi sunma & 1 \\
Öğretimde düzenliliği sağlama & 1 \\
Öğretimin verimliliğini arttırma & 1 \\
Genel kültürü artırma & 1 \\
Motivasyonu artırma & 1 \\
Dikkat çekme & 1 \\
İlgiyi ve başarıyı arttırma & 1 \\
\hline Dikkat toplama & 5 \\
Öğrenci seviyesine uygun olmama & 3 \\
Zamanın ayarlanamaması & 3 \\
Konu ile ilişkilendirilmeme & 3 \\
Not tutturulmama & 1 \\
Güncel materyal bulamama & 1 \\
Anlam karmaşası & 1 \\
Sıkılma & 1 \\
Diğer metotların sıkıcı ve sıradan gelmesi & 1 \\
Başarının düşmesi & 1 \\
\hline
\end{tabular}




\section{Fen Eğitiminde Görsel Medyadan Yararlanmada Karşılaşılabilecek Sorunlar}

Fen eğitiminde görsel medyadan yararlanmada karşılaşılabilecek sorunlar ile ilgili öğretmen görüşleri teknolojik donanım, kaynak ve zaman başlıkları altında ele alınabilir. Tablo 3'te de görüldüğü üzere teknolojik donanım teması altındaki görüşler teknolojik donanım yetersizliği ve öğretmenlerin teknolojik bilgi yetersizliği olarak çeşitlenmektedir. Teknolojik donanım yetersizliği hakkında bir öğretmenin (K-1) görüşü "Ortamda medya malzemelerinin kullanılması sırasında yardıma malzemelerin (örneğin ses düzeni) yetersiz olması sorun olarak yaşanabilir" şeklindeyken diğer bir öğretmen (K-5) "Okullarda özel TV kanalları vs. olmadığı için belgesel, bilimsel deneyler gösterilemiyor. Ayrıca internet bağlantıları kesildiği için sunum yarıda kalıyor. Dersi toplayabilmek için tekrar zaman kaybı yaşanıyor" şeklindedir. Bunun dışında öğretmenlerin teknolojik bilgi yetersizliği hakkındaki görüşlerden birisi (K-2) "Görsel araçların kullanılmasında kullanıcının eğitim ve kullanım becerisi ile ilgili eğitim düzeyi" şeklinde yer alırken, diğer bir öğretmenin (K-13) "Öğretmenler kullanılan materyal hakkında bilgi sahibi olmayabilir" şeklinde yer almıştır.

Tablo 3.

Fen Eğitiminde Görsel Medyadan Yararlanmada Karşılaşılabilecek Sorunlar.

\begin{tabular}{llc}
\hline Tema & Alt tema & $\mathbf{f}$ \\
\hline Teknolojik donanım & Teknolojik donanım yetersizliği & 5 \\
& Öğretmenlerin teknolojik bilgi yetersizliği & 3 \\
\hline Kaynak & Konulara göre görsellerin olmaması & 4 \\
& Ekonomik & 4 \\
& Öğrenci düzeyine uygun olmama & 3 \\
\hline Zaman & Sınav sistemi nedeniyle zaman kaybı olduğunun sanılması & 2 \\
& Programı yetiştirememe & 1 \\
& Ön hazırlık gerektirmesi & 1 \\
\hline
\end{tabular}

Kaynak teması altında çoğunlukla konulara göre görsellerin olmaması ve ekonomik olmamaya vurgu yapılmıştır. Bu konu ile ilgili bir öğretmenin (K-10) görüşü "Tam olarak konu, amaç ve kazanımlara uygun materyallerin yetersizliği" şeklindeyken diğer bir öğretmenin (K-11) görüşü "Güncel konulara göre (cd, film, animasyon ve video çekimleri) materyal bulunmaması" şeklinde olmuştur. Ekonomik olmama alt teması altında incelen bir katılımcı (K-11) görüşünü "Kaynakların paralı ve pahalı olması" şeklinde dile getirirken diğer bir öğretmen (K-4) "Fen ve teknoloji dersinde kullanılan görsellerin kullanımında bazı sitelerin şifre istemesi, ücretli olması" şeklinde dile getirmiştir. Başka bir öğretmen (K-3) ise görüşünü şu şekilde paylaşmıştır: "Belgesellerle ilgili olarak 5-6 yıl önce NTV de izlediğim bir belgesel (bitkilerin çoğalması için geliştirdikleri yöntemler konusunda) çok ilgimi çekti. Öğrencilerim de izlesin diye kanala telefon açtım. ilgili CD yi istedim. Durumu anlattım. National Geographic Channel'a anlaşmaları olduğu için veremeyeceklerini söylediler. (yetkili). Atatürk belgeseli ile yine bir Tv programından yardım istedim. TV kanalı sadece oyaladı. Yardımcı olmuyorlar".

Kaynak teması altında en az tekrarlanan alt tema ise öğrenci düzeyine uygun olmamadır. Bu alt tema ile ilgili bir öğretmeninin (K-13) görüşü "Kullanılan materyal öğrencinin bilişsel ve pedagojik özelliklerine uygun olmayabilir" şeklindeyken bu görüşü paylaşan diğer bir görüş (K-14) ise şu şekildedir: "Öğrenciye bir konu görsel medyadan araştırmak üzere verildiğinde yeterli rehberlik yapılmazsa yaş seviyesini zorlama ihtimali ortaya çıkar ve öğrencinin derse ve özellikle fen ile ilgisi azalabilir. Öğrenciler genellikle bilimsel haber diye gazetelerden tıp ile ilgili şifa ile ilgili bilgiler getiriyorlar. Bunları fen dersi ile ilgili haber zannediyorlar. Bu algı onlar için normal. Ama öğretmen burada devreye girmezse, hangi haberin fen dersi ile ilgili olup olmadığını anlatmazsa öğrenci de tam anlamıyla yararlanamaz. Amaca ulaşılmaz".

Zaman teması altında çoğunlukla sınav sistemi nedeniyle zaman kaybı olduğunun sanılmasına vurgu yapılmıştır. Bu konu ile ilgili görüş bildiren öğretmenlerden biri (K-11) görüşünü "Sınav sistemi nedeniyle film göstermenin zaman kaybı olduğunun sanılması" şekilde ifade ederken başka bir öğretmen (K-15) 
"Uzun zaman alması" şeklinde ifade etmiştir. Zaman teması altında vurgulanan diğer alt temalar ise programı yetiştirememe ve ön hazırlık gerektirmesidir.

\section{Görsel Medyanın Fen Derslerinde Etkili Bir Biçimde Kullanılabilmesi Konusunda Öğretmenlerin Önerileri}

Görsel medyanın fen derslerinde etkili bir biçimde kullanılabilmesi konusunda öğretmenlerin önerilerine ilişkin öğretmen görüşlerinin kaynak, Milli Eğitim Bakanlığı, öğretmen, teknolojik donanım ve öğrenci ile ilgili olduğu görülmektedir (Tablo 4). Kaynak teması altında görüşlerin çoğunlukla görsellerin kısa ve dikkat çekici olması, görsellerin ünite ve kazanımları kapsaması, materyal çeşitliliği ve seviyeye uygun olma alt temalarında olduğu görülmektedir.

Görsellerin kısa ve dikkat çekici olması ile ilgili bir öğretmenin görüşü (K-11) "Filmler, animasyonlar, ders saati içinde, dersin sonuna doğru kısa ve dikkat çekici olmalı" şeklinde olmuştur. Görsellerin ünite ve kazanımları kapsaması ile ilgili yine aynı öğretmen (K-11) "Görseller ünite ve konuları kapsamalı ve disiplinler arasında olmalı. Yani fen anlatılırken tarih ve matematik konuları da verilebilir" şeklinde görüşünü belirtmiştir. Materyal çeşitliliği alt teması ile ilgili bir öğretmenin (K-10) ise görüşünü "Materyal yeterli olursa daha etkin kullanılabilir" şeklinde paylaşmıştır. Seviyeye uygun olma alt teması ile ilgili bir öğretmen (K-5) ise görüşünü şu şekilde ifade etmiştir: "5. ve 6. Sınıflarda çizgi film ve animasyonlar öğrencilerin çok ilgisini çekiyor. Aradan yıllar geçtiğinde bile öğrenciler bunu unutmuyor. 7. ve 8. Sınıf öğrencileri ise ergenliğe girdikleri için çizgi filmi çocuksu bulduklarını söyleyip, daha ciddi anlatımlar istediklerini belirtiyorlar".

Tablo 4.

Görsel Medyanın Fen Derslerinde Etkili Bir Biçimde Kullanılabilmesi Konusunda Öğretmenlerin Önerileri.

\begin{tabular}{lll}
\hline Tema & Alt tema & $\mathbf{f}$ \\
\hline Kaynak & Görsellerin kısa ve dikkat çekici olması & 2 \\
& Görsellerin ünite ve kazanımları kapsaması & 2 \\
& Materyal çeşitliliği & 2 \\
& Seviyeye uygun olma & 2 \\
& Güncel olmalı & 1 \\
& Ücretsiz sunulma & 1 \\
& Amaca uygun kullanılma & 1 \\
& Seslendirme & 1 \\
& Kolayca bulunabilmesi & 1 \\
\hline MEB & Öğretmenlerin Hí almaları & 3 \\
& Görsellerin MEB tarafından sağlanması & 3 \\
& Görseller için ayrı bir sınıf oluşturulması & 1 \\
& Zaman ayarlaması & 1 \\
\hline Öğretmen & Ön hazırlık yapılmalı & 2 \\
& Derste zaman zaman görsellerin kullanılması & 1 \\
& Etkin bir şekilde takip etmesi & 1 \\
\hline Teknolojik Donanım & Teknolojik donanımların olması & 2 \\
& Okulların alt yapısı düzenlenmeli & 1 \\
\hline Öğrenci & Beceri kazanma & 2 \\
& Merak uyandırma & 1 \\
& Zengin içerik & 1 \\
\hline
\end{tabular}

Kaynak teması altında en az tekrarlanan diğer alt temalar ise güncel olmalı, ücretsiz sunulma, amaca uygun kullanılma, seslendirme ve kolayca bulunabilmesidir. Kolayca bulunabilme ile ilgili bir öğretmen (K-1) görüşünü "internette araştırma yapacaklara adreslerin verilmesi" şeklinde ifade etmiştir. 
MEB teması altında öğretmenlerin çoğunlukla HIE almaları ve görsellerin MEB tarafından sağlanmasıyla ilgili görüş belirttikleri görülmektedir. Öğretmenlerin Hi̇E almaları ile ilgili bir öğretmen (K8) "Öncelikle öğretmenlerin bu konuda hizmet içi eğitim alınması gerekir" şeklinde görüş bildirirken diğer bir öğretmen (K-13) "Öğretmenlere bu konu da uygulamaya yönelik hizmet içi eğitim imkânı verilmelidir" şeklinde görüşünü ifade etmiştir. Görsellerin MEB tarafından sağlanması alt teması ile ilgili de bir öğretmenin (K-3) görüşü "Bu konuyla MEB belgesel kanallarıla anlaşmalar yapabilir. Bu CD'ler ve kaynakları okullara aktarabilirler" şeklindeyken diğer bir öğretmenin görüşü ise "Kişisel başvurular pek göz önüne alınmadığı için bu konuyu bizzat Milli Eğitim Bakanlığı çözmelidir" şeklindedir. Başka bir öğretmenin (K-8) görüşü ise şu şekildedir: "Konulara ait deney, slayt, resim vb. MEB sitesinden en kolay şekilde sağlanması gerekir". MEB teması içinde en az tekrarlanan alt temalar ise görseller için ayrı bir sınıf oluşturulması ve zaman ayarlamasının yapılması ile ilgilidir.

Öğretmen teması altında en çok tekrarlanan görüş ise ön hazırık yapılmalı şeklinde olmuştur. Bu alt tema ile ilgili bir öğretmen (K-10) "Ön hazırlık iyi yapılırsa daha iyi kullanılabilir" şeklinde görüş belirtirken, bu görüşü destekleyen diğer bir görüş (K-9) ise "Öğretmen görsel malzemeyi genellikle internetten hazır olarak alıp kullanmakta. Internetten indirilen film, slayt, animasyon öğretmen tarafından gözden geçirilip, düzenlenip, gereksiz kısımlar çıkartılarak kullanılırsa bilgi kirliliği ortadan kalkar ve zaman kaybı önlenir" şeklindedir. Öğretmen teması altında en az tekrarlanan görüşler ise derste zaman zaman görsellerin kullanılması ve etkin bir şekilde takip etmesi olarak ifade edilmiştir.

Teknolojik donanım teması altında öğretmenlerin çoğunlukla teknolojik donanımların olmasını ifade ettikleri görülmektedir. Teknolojik donanımla ilgili bir öğretmen (K-4) "Görsel medyanın etkili bir biçimde fen ve teknoloji dersinde kullanılabilmesi için bilgisayar, projeksiyon ve internet malzemelerinin okullarda tam ve kullanılabilir olması gerekmektedir" şeklinde görüşünü ifade ederken bu görüşü paylaşan diğer bir görüş (K-7) ise "Teknolojik donanımların yeterli olması" şeklinde olmuştur. Teknolojik donanım teması altında en az tekrarlanan görüş ise okulların alt yapısının düzenlenmesi olmuştur.

Öğrenci teması altında öğretmenlerin çoğunlukla belirttikleri görüş ise beceri olmuştur. Bu konuyla ilgili bir katılımcı (K-12) görüşünü "Keşfetme, düşünmenin keyfine vardırmak, çözüm yollarına ulaştıracak beceriler kazanmasını sağlamak" şeklinde ifade etmiştir. Öğrenci temasında en az tekrarlanan görüşler ise merak uyandırma ve zengin içerik alt temalarında olmuştur.

\section{Sonuç, Tartışma ve Öneriler}

Fen ve teknoloji öğretmenleri çoğunlukla görsel medyanın kalıc öğrenmelere neden olduğu ve anlamayı kolaylaştırdığı ile ilgili görüş bildirmişlerdir. Yalçın, Yiğit, Sülün, Bal, Başbuğ ve Aktaş (2003) tarafından yapılan maddeyi tanıma ünitesinin kavratılmasında görsel materyallerin etkisinin araştırıldığı çalışmada rüzgâr, hava, ısı, elektrik gibi hissedilebilir kavramlarının öğretiminde de görsel materyallerin rolünün etkili olduğu anlaşılmıştır. Ayrıca öğretmenler görsel medyanın ilgi ve merakı artırdığı yönünde de görüşlerini ifade etmişlerdir. Bunlara ek olarak görsel medyanın fen eğitimine katkılarına yönelik öğretmen görüşleri arasında görsel medyanın zaman tasarrufu sağlama ve öğretmenin yükünü azaltma vurgulanmıştır. Öztürk, Demir ve Dökme (2011) tarafından yapılan bir çalışmada teknolojik aletlerin eğitimde zamandan tasarruf sağlaması, dikkati çekmesi, görsellik ve öğrenmede kalıcılık sağlamasından dolayı yararlı olabileceği sonucuna varılmıştır.

Öğretmenlerin görsel medyanın öğrenmeyi kolaylaştırdığı, öğretmenin anlatımını kolaylaştırdığı, dersi zevkli hale getirdiği, merakı artırdığı ve kalıcı öğrenmeyi sağladığı şeklinde olumlu görüş bildirdikleri görülmüştür. Mandıracıoğlu, Hassoy ve Karababa (2011) tarafından yapılan bir çalışmada birinci sınıf öğrencilerinin film kullanımına ilişkin olumlu bulduğu özellikler; film gösterimi ile konuların akılda daha kalıcı olması, görsel olması, gerçek yasamdan somut örnekler göstermesi, teorik dersin pekişmesini ve anlaşılmasını sağlaması, öğrenci katılımını sağlaması, interaktif olması, eğlenceli ve zevkli öğrenme yaşatması, konunun daha kolay anlaşılması ve öğrenilmesi şeklinde gruplandırılmıştır. Bununla birlikte öğretmenler çoğunlukla görsel medyanın dikkat toplamada sıkıntı yaratacağını vurgulamışlardır. 
Mandıracıoğlu vd. (2011) tarafından yapılan çalışmada öğrenciler olumlu görüşlerinin yanı sıra eleştirilerini de bildirmişlerdir. Bunlar; bazı filmlerin uzun olması, sıkıcı olması, uyku getirmesi, teknik sorun olması, müziklerin dikkat dağıtıcı olması şeklinde sınıflanmıştır. Yapılan bu çalışmanın bulguları incelendiğinde de görsel medya kullanımları sırasında sıkılmanın az da olsa yine öğretmenler tarafından ifade edildiği görülmektedir. Mandıracıoğlu vd. (2011) tarafından yapılan çalışmanın sonuçları bu araştırmanın sonuçlarıyla paralellik göstermektedir.

Fen eğitiminde görsel medyadan yararlanmada karşılaşılabilecek sorunlar ile ilgili öğretmen görüşleri incelendiğinde öğretmenlerin çoğunlukla teknolojik donanım yetersizliğini vurgulandığı görülmektedir. Görsel medyanın fen derslerinde etkili bir biçimde kullanılabilmesi konusunda öğretmenler çoğunlukla hizmet içi eğitim almaları ve görsellerin Milli Eğitim Bakanlığı tarafından sağlanması gerektiği konusunda önerilerde bulunmuşlardır. Ökten ve Horzum (2011)'un yaptığı nitel bir araştırmada öğretmenler, teknolojinin hızla gelişmesi ve değişmesinden dolayı gerekli yeterlikleri takip edemediklerini, bilgisayar kursu almalarına rağmen öğrencilerine sadece basit düzeyde bilgisayar yeterliliklerini kazandırabileceklerini ifade etmişlerdir. Fakat mevcut öğretim programları ve özellikle FATiH projesi, öğretmenlerin teknolojiyi eğitimde etkili olarak kullanmalarını beklemektedir. Öğretmenler kendilerine hizmet öncesi verilen derslerde, teknoloji ve bilgisayar kullanma bilgi-becerisini yeterli düzeyde alamadıklarını belirtmektedirler (Erdemir, Bakırcı ve Eyduran, 2009).

Araştırma sonuçları doğrultusunda çeşitli önerilere yer verilmiştir. Öğretmenler görsel medyanın kalıcı öğrenmeye neden olduğu, anlamayı kolaylaştırdığı, ilgi ve merakı artırdığı ve zaman tasarrufu sağladığı yönünde görüşler bildirmişlerdir. Derslerde öğretmenlerin görsel medyadan yararlanmalarını sağlayacak çalışmalar yapılmalıdır. Öğretmenler derslerinde görsel medya kullanırken teknolojik donanım yetersizliği, konulara göre görsellerin olmaması, mevcut görsellerin ekonomik olmaması gibi sorunlara karşılaşabilmektedir. Bu sorunların giderilmesi için her konuya yönelik olarak görseller geliştirilmeli, programlarda görsel öğrenme yer almalı, öğretmenler derslerinde görsel öğrenme yöntemlerinden filmlerden, animasyonlardan, belgesellerden, çizgi filmlerden yararlanmalıdır. Öğretmenlere teknolojik donanım kullanmalarına yönelik eğitimler verilmelidir. Her ünite, konu ya da kazanımla ilişkilendirilebilecek görseller MEB tarafından hazırlanmalı ve öğretmenlerin erişebileceği bir siteme yüklenmelidir.

Sonuçta, yapılan bu araştırma fen bilgisi öğretmenlerinin fen ve teknoloji dersinde görsel medya kullanımına yönelik düşüncelerini ortaya koyması bakımından önemlidir. Öğrencilerin günlük yaşamda pek çok görsel öğrenme araçlarıyla etkileşim içerisinde olduğu açıktır. Bu bakımdan öğretmenlerin görsel öğrenme araçlarını derslerinde kullanmaları gereklidir. Bu araştırmada konunun özelliğinden dolayı bazı sınırılıklar mevcuttur. Her şeyden önce veri toplama aracı çeşitliliğine gidilememiş, sadece görüşme yapılabilmiştir. Gelecekte yapılacak daha geniş kapsamlı, daha uzun süreli, daha fazla veri toplama aracının ve çeşitli araştırma yöntemlerinin bir arada kullanılacağı araştırmalar alana büyük katkı sağlayacaktır. 


\section{Kaynakça}

Arıkan, A. (2009). Edebiyat öğretiminde görsel araç kullanımı: Kısa öykü örneği. Ondokuz Mayıs Üniversitesi Ĕgitim Fakültesi Dergisi, 27, 1-16.

Birkok, M., C. (2008). Bir toplumsallaştırma aracı olarak eğitimde alternatif medya kullanımı: Sinema filmleri. Uluslararası insan Bilimleri Dergisi, 5(2), 1-12.

Blasco, P. G., Moreto G., Roncoletta A. F. T., Levites M. R., \& Janaudis M. A. (2006). Using movie clips to foster learners'reflection: Improving education in the affective domain. Family Medicine, 38(2), 9496.

Erdemir, N., Bakırcı, H., \& Eyduran, E. (2009). Öğretmen adaylarının eğitimde teknoloji kullanabilme özgüvenlerinin tespiti. Türk Fen Eğitimi Dergisi, 6(3), 99-108.

Hammerberg, D. (2001). Reading and writing "hypertextually": Children's literature, technology, and early writing instruction. Language Arts, 78, 207-215.

Hashemzadeh, N. \& Wilson, L. (2007). Teaching with the lights out: what do we really know about the impact of technology intensive instruction? College Student Journal, 41(3), 601-612.

Kuzma, L. M. (2001). And, action! Using film to learn about foreign policy. International Studies Perspectives, 2(1), 33-50.

Luis Alvarez, J., Miller, P., Levy, J., \& Svejenova, S. (2004). Journeys to the self: Using movie directors in the classroom. Journal of Management Education, 28(3), 335.

Mandıracıoğlu, A., Hassoy, H. \& Karababa, A. O. (2011). Halk sağlığı eğitiminde film kullanımı. Tıp Eğitimi Dünyası, 31, 17-28.

Mayer, R. E. \& Moreno, R. A. (1998). Cognitive theory of multimedia learning: Implications for design principles. Journal of Educational Psychology, 91(2), 358-368.

MEB (2006). ilköğretim fen ve teknoloji dersi öğretim programı. Ankara: MEB.

Ökten, G. \& Horzum, M. B. (2011). Sınıf öğretmenlerinin bilişim teknolojileri dersi öğretimine yönelik görüşleri üzerine nitel bir çalışma. 5. Uluslararası Bilgisayar ve Öğretim Teknolojileri Sempozyumu, 22 -24 Semptember 2011, Elazığ.

Öztürk, N., Demir, R. \& Dökme, İ. (2011). Fen bilgisi öğretmenliği öğrencilerinin eğitimde teknoloji kullanımına ilişkin tutumları ve görüşleri. 2nd International Conference on New Trends in Education and Their Implications. 27-29 April, 2011 Antalya-Turkey.

Patton, M. Q. (2001). Qualitative research and evaluation methods (2nd Edition). Thousand oaks, CA: Sage Publications.

Shaw, D. G., \& Dybdahl, C. S. (2000). Science and the popular media. Science Activities: Classroom Projects and Curriculum Ideas, 37(2), 22-31.

Sorenson, D. S. \& Dieter, C. (2005). From beginning to end video-based introductory, instructional, and evaluation applications. Nurse Educator, 30(1), 40-43.

Sürmeli, H. (2013). Fen ve matematik eğitiminde teknolojik pedagojik alan bilgisi temelli öğretim tasarımları. In T. Y. Yelken, H. S. Tokmak, S. Özgelen \& L. İncikabı. (Ed.), Bilim kurgu filmlerinin desteği ile TPAB temelli-fen teknoloji toplum dersi tasarımı (pp. 149-164). Ankara: Anı Yayıncılık.

Weber, C. M. \& Silk, H. (2007). Movies and medicine: An elective using film to reflect on the patient, family, and illness. Family Medicine, 39(5), 317-319. 
Munise SEÇKIN KAPUCU - Pegem Eğitim ve Öğretim Dergisi, 4(2) 2014, 75-90

Yalçın, P., Yiğit, D., Sülün, A., Bal, D. A., Başbuğ, A., \& Aktaş, M. (2003). Maddeyi tanıma ünitesinin kavratılmasında görsel öğretim materyallerinin etkisi üzerine bir araştırma. Kastamonu Eğitim Dergisi, 11(1), 115-120.

Yıldırım, A. \& Şimşek, H. (2008). Sosyal bilimlerde nitel araştırma yöntemleri. Ankara: Seçkin Yayıncılık. 